\title{
Tumor microenvironment is not an 'innocent bystander' in the resistance to treatment of head and neck cancers (Review)
}

\author{
LAURA MAZILU ${ }^{1}$, ANDRA-IULIA SUCEVEANU ${ }^{2}$, DANA-LUCIA STANCULEANU ${ }^{3}$, \\ ANDREEA-DANIELA GHEORGHE ${ }^{1}$, GABRIELA FRICATEL $^{1}$ and SERBAN-MIRCEA NEGRU ${ }^{4}$ \\ Departments of ${ }^{1}$ Oncology and ${ }^{2}$ Gastroenterology, 'Ovidius’ University, 900527 Constanţa; \\ ${ }^{3}$ Department of Oncology, 'Carol Davila' University of Medicine and Pharmacy, 050474 Bucharest; \\ ${ }^{4}$ Department of Oncology, 'Victor Babes' University of Medicine and Pharmacy, 300041 Timisoara, Romania
}

Received June 8, 2021; Accepted July 8, 2021

DOI: $10.3892 / \mathrm{etm} .2021 .10562$

\begin{abstract}
Head and neck cancers are still one of the most common types of cancer in the world. They rank in the leading sixth place in terms of incidence globally, and the incidence continues to rise. The mortality rates remain at high levels. Pathological subclassification places squamous cell carcinoma of the head and neck (HNSCC) in the first place concerning the histological forms of head and neck cancers; a tumor with extremely aggressive behavior and high mortality rates. The tumor microenvironment is a very complex ecosystem of cellular and non-cellular components, characterized by unique features, that contribute to the appearance of immunosuppression and diminished anticancer immunity, impacting patient prognosis and treatment outcome. Despite many important advances in therapy, resistance to therapy represents a difficult challenge in HNSCC patients. Tumor progression, metastasis, and response to therapy are all influenced by the complex ecosystem represented by the tumor microenvironment and by
\end{abstract}

Correspondence to: Professor Laura Mazilu, Department of Oncology, 'Ovidius' University, 124 Mamaia Boulevard, 900527 Constanţa, Romania

E-mail: lauragrigorov@gmail.com

Abbreviations: DFS, disease-free survival; dMMR, mismatch repair deficiency; EGFR, epidermal growth factor receptor; GM-CSF, granulocyte-macrophage colony-stimulating factor; HNSCC, squamous cell carcinoma of the head and neck; HPV, human papillomavirus; ICIs, immune checkpoint inhibitors; JAK, janus kinase; MAPKs, mitogen-activated protein kinases; MCP-1, monocyte chemo-attractant protein 1; MSI, microsatellite instability; mTOR, mammalian target of rapamycin; OS, overall survival; PI3K, phosphoinositide 3-kinase; PKC, protein kinase C; TGF- $\beta$, transforming growth factor $\beta$; VEGF, vascular endothelial growth factor; TMB, tumor mutational burden; TME, tumor microenvironment; TNF- $\alpha$, tumor necrosis factor $\alpha$

Key words: head and neck cancers, tumor microenvironment, biomarkers of response, squamous cell carcinoma, microsatellite instability, microbiota the interactions between cellular and non-cellular components of this system. Therefore, the tumor microenvironment, in the light of recent data, is not an innocent bystander. In the last few years, there has been a sustained effort to characterize the tumor microenvironment, to identify targets of response and identify other mechanisms of tumor-specific immune responses, or to discover other biomarkers of response. There is an urgent need to understand how to properly select patients, the therapy sequence, and how to use feasible biomarkers that can help to identify the patient who may obtain the most benefit from available therapies.

\section{Contents}

\section{Introduction}

2. Tumor microenvironment in head and neck cancer

3. Tumor microenvironment-related resistance to treatment in head and neck cancers

4. Strategies to fight TME: Treatment resistance in head and neck cancers

5. Tumor immune infiltration

6. T cell-inflamed gene expression profile

7. Microsatellite instability (MSI)

8. Microbiota

9. Smoking status

10. Conclusions

\section{Introduction}

Head and neck cancer is one of the most common types of cancer in the world, ranking in the sixth place in terms of global incidence. The incidence continues to rise, and the mortality rates remain at high levels $(1,2)$. Epidemiological data show that starting from 1997, the incidence is decreasing for nasopharyngeal and larynx cancers, but remains increased for hypopharyngeal, oropharyngeal, and oral cavity cancers. The highest incidence is found in Asia, followed by Europe and North America. Pathological subclassification places squamous cell carcinoma of the head and neck (HNSCC) at the top of the histological forms (90\%) of head and neck 
cancers; a tumor with extremely aggressive behavior and a high mortality rate of $50 \%$ at 5 years $(3,4)$.

HNSCC is a very heterogeneous group of cancers that have high variability in terms of tumor location, histological subtype, molecular characteristics, and prognosis (5-7).

Well-known risk factors for HNSCC are smoking and alcohol consumption; $75 \%$ of HNSCC cases are caused by smoking and alcohol, the effect of those two major factors being difficult to separate. The role of alcohol in the risk of head and neck cancer is dose-related, and the risk is increased by the association of smoking. Human papillomavirus (HPV) infection is associated with oropharyngeal cancer; the incidence rate of oropharyngeal cancer depends on the geographical area, but is increasing worldwide, and is expected to exceed the incidence rates of cervical cancers $(8,9)$. The main risk factor in the Asian continent, and especially in the south of Asia is the use of smokeless tobacco products, for example, gutkha, pan masala, as well as chewing betel or areca nuts (10-12). Other factors involved in the increasing risk of HNSCC are exposure to asbestos, wood dust or prior irradiation, use of salty foods, deficient oral hygiene, and viral infections (Epstein-Barr virus for nasopharyngeal cancer, and human immunodeficiency virus) (13-17). Essential measures to reduce the incidence of head and neck cancers include health policies to reduce smoking habits and alcohol intake, protection of workers from exposure to carcinogens, and education of the population for a healthy lifestyle and diet.

HNSCC is mostly diagnosed at a locally advanced stage or with distant metastases. HNSCC treatment involves a multidisciplinary team approach, composed mainly of surgeons, radiotherapists, and oncologists. Available systemic therapeutic options include chemotherapy, targeted therapy, and immunotherapy. However, despite multidisciplinary therapeutic interventions, up to $60 \%$ of locally advanced tumors eventually show local recurrence or progression, and the prognosis of metastatic HNSCC remains extremely poor (5-7).

Following approval of cetuximab and its addition to the chemotherapy regimen, patient outcome has improved. Still, the mean overall survival remains approximately 10 months (18). The addition of immune checkpoint inhibitors (ICIs) in the therapeutic panel of these patients, has led to further improvements in the outcomes of patients with metastatic HNSCC, but the results remain at lower levels compared to renal cancer, melanoma, or lung cancer $(19,20)$.

A complete understanding of the tumor biology of HNSCC could help in defeating the treatment resistance of these tumors and could also help in the development of new therapeutic strategies. Therefore, it is imperative to understand the biology of HNSCC and to identify new therapeutic targets for the effective management of this malignancy $(5,21)$.

Most of the previous therapeutic trials have targeted cancer cells, but recent studies have shown that the tumor microenvironment (TME) formed by nearby cancer cells and extracellular proteins play a significant role in cancer formation, in the progression of the disease, and also in the pathways of resistance to treatment (22). In light of the recent data, the tumor microenvironment is not 'an innocent observer', but an important player representing a suitable environment for the formation and progression of cancer and metastasis, and plays also a role in the development of treatment resistance.
This conclusion is sustained by multiple clinical trials, not only for head and neck cancers but for a plethora of malignancies (23-27).

Many of the cellular components (T-regulatory cells, cancer-associated fibroblasts, and macrophages), together with other non-cellular constituents of the tumor microenvironment (for example extracellular matrix), are associated with a compromised immune status and immune cell dysfunction of cytotoxic T cells or dendritic cells (25).

HPV infection and smoking are responsible for a distinct type of immune tumor microenvironment, with a different behavior $(28,29)$.

In the era of immunotherapy, to obtain better responses to treatment, it is mandatory to understand the complexity of this ecosystem represented by the tumor microenvironment of head and neck cancers.

In this review, we take a journey into the complexity of the tumor microenvironment of the patients with HNSCC cancer, HPV-positive or -negative, and its involvement in the development of treatment resistance. We also review the potential therapeutic strategies under investigation that can overcome the resistance induced by the tumor microenvironment.

\section{Tumor microenvironment in head and neck cancer}

Historically, cancer has been categorized as an accumulation of undifferentiated tumor cells forming a tumor mass, without taking into consideration any of the cells that are present in the environment surrounding these cancer cells. Currently, the tumor microenvironment is defined as a very complex ecosystem of cellular and non-cellular components, that are continuously evolving, characterized by unique features, that lead to immunosuppression and diminished anticancer immunity. The cellular components are represented by modified stromal cells (cancer-associated fibroblasts, endothelial cells, adipocytes, neuroendocrine cells, blood cells), and infiltrating immune cells (T cells, B cells, natural killer cells, dendritic cells, macrophages, and myeloid-derived suppressor cells) $(25,30,31)$. The non-cellular components of the tumor microenvironment are proteins of the extracellular matrix (collagen, fibronectin, elastin, laminin, tenascin) that influence proliferation, invasion, metastases, and survival of the cancer cells. All these components also help the cancer cells to escape immune recognition, providing a friendly environment for tumor progression, metastases, and the development of resistance to therapy (32-34).

The tumor microenvironment of HNSCC is infiltrated with lymphocytes called tumor infiltrated lymphocytes (TILs). TILs are represented by subsets of cells, that include T-helper cells $\left(\mathrm{CD}^{+}\right)$, cytotoxic T cells $\left(\mathrm{CD}^{+}\right)$, T-regulatory cells (T-regs), macrophages $\left(\mathrm{CD}^{+} 8^{+}\right.$and $\left.\mathrm{CD}^{2} 63^{+}\right)$, natural killer cells $\left(\mathrm{NKCD} 57^{+}\right)$, and myeloid-derived suppressor cells (MDSCs) (35). All cellular elements of the tumor microenvironment assign prognostic importance to TILs. Despite important infiltration with pro-inflammatory cells, the tumor microenvironment of HNSCC is immunosuppressive. This is because TILs have functional defects represented by decreased secretion of cytokines and decreased expression of CD3 zeta chain, losing the skill to kill cancer cells $(32,36,37)$. T-regs represent the majority of $\mathrm{T}$ cells in the 
tumor microenvironment. Regulatory $\mathrm{T}$ cells are capable to build an immune-suppressive wall by blocking the activity of the effector T cells (38). In addition, there is a decreased number of NK cells and dendritic cells in the tumor microenvironment of HNSCC patients that is responsible for the immunodeficiency induced by the tumor $(39,40)$. Expression of mediators with pro-inflammatory activity has a definitive impact on tumor progression and metastasis [interleukins, E2 prostaglandin, granulocyte-macrophage colony-stimulating factor (GM-CSF), tumor necrosis factor (TNF)- $\alpha$, transforming growth factor (TGF)- $\beta$, monocyte chemo-attractant protein 1 (MCP-1), and vascular endothelial growth factor (VEGF)] $(41,42)$.

Depending on HPV status, there are many differences between HPV-negative and HPV-positive populations (43). The HPV-negative HNSCC frequently occurs in the lip, tongue, hard palate, and buccal mucosa. HPV-positive HNSCC is frequently observed in the palatine and lingual tonsillar regions (44).

HPV-negative patients are older comparing to HPV-positive patients (45-47). The mutations found in HPV-negative HNSCC patients are represented by TP53, NOTCH, CCND1, CDKN2A, CUL3, FGFR1, MLL2, NSD1, while in HPV-positive HNSCC patients there is a higher mutational incidence of PIK3CA, DDX3X, FGFR2, FGFR3, KRAS, MLL3, and NOTCH-1 (48). An increased number of cancer stem cells with a high expression of BIM1, KLF4, OCT4, or SOX2 was observed in HPV-negative patients (49), and the expression of these markers on the cancer stem cell is associated with a low response to chemo-radiotherapy and a negative impact on the patient's overall survival (OS) $(50,51)$.

Some studies have shown that compared with HPV-negative HNSCC patients, HPV-positive HNSCC tumors have in the intraepithelial and stromal compartments a significantly high number of T-regs that are FOXP $3^{+}$, and this was associated in some studies with better disease-free survival (DFS) and overall survival (OS), while other studies reported inferior data $(5,51-53)$.

A higher infiltration of $\mathrm{T}$ cells $\left(\mathrm{CD}^{+}\right.$and $\left.\mathrm{CD}^{+}\right)$and higher $\mathrm{CD}^{+}$TILs was reported in HPV-positive oropharyngeal cancers, compared with HPV-negative tumors, and this feature was strongly associated with better local control of the disease, better prognosis, and improved OS $(5,54,55)$.

Tumor-associated macrophages have an important role in the genesis of tumors, angiogenesis and invasion, and local immunosuppression. Increased infiltration of $\mathrm{CD}^{+} 8^{+}$macrophages has been observed in HNSCC patients, and this feature is related to lymph node metastasis, and has a negative impact on DFS and OS $(56,57)$.

Regarding CD56 ${ }^{+} \mathrm{NK}$ cells, an increased expression was reported in HPV-positive patients and it was correlated with an improvement in OS $(5,58,59)$.

Langerhans cells are the antigen-presenting cells of the immune system and a decreased number of these cells is associated with compromised immune surveillance. A higher infiltration of Langerhans cells was observed in HPV-negative tumors comparing with HPV-positive tumors, and this characteristic was correlated with improved DFS and OS. The mechanism by which the recruitment of Langerhans cells is affected is not fully understood but it seems to be related to a decrease in E-cadherin and macrophage inflammatory protein $3(60-62)$.

The role of TP53 in the promotion of immune infiltration in HPV-positive patients with HNSCC is well known, but the underlying mechanisms are not yet fully established (63). Several studies suggest that the tumor microenvironment of HPV-positive tumors, rich in E6 and E7 proteins evade the immune response, which results in persistent HPV infection, and that the increased secretion of IL-10 and TGF- $\beta$ from T-regs prevents clearance of HPV infection. More than that, HPV E5 protein prevents NK cells to recognize infected cells (63-65).

HPV-positive and HPV-negative tumors are also different in terms of metabolic activity, as shown by recent data. These metabolic differences are represented by increased oxidative phosphorylation and higher rates of aerobic glycolysis found in HPV-positive tumors compared with HPV-negative tumors, consequently influencing the tumor microenvironment (5).

The role of the tumor microenvironment in the progression and metastasis of HNSCC is related to the secretion of many different cytokines, chemokines, growth factors, and hormones. These factors are released by stromal cells, as well as by cancer cells. This secretion activates different pathways, such as the epidermal growth factor receptor (EGFR), Janus kinase (JAK), mammalian target of rapamycin (mTOR), mitogen-activated protein kinases (MAPKs), phosphoinositide 3-kinase (PI3K) or protein kinase $\mathrm{C}$ (PKC) pathways (66). All these pathways are known to be involved in regulation of the cell cycle, tumor growth, differentiation, invasion, metastasis, angiogenesis, apoptosis, immune surveillance, or therapeutic response.

Smoking, a common risk factor for HNSCC, is responsible for pro-inflammatory and immunosuppressive states, impacting the tumor microenvironment and facilitating tumor development. The accumulation of immunogenic neoantigens is a phenomenon highly evident in smoking-related cancers. These neoantigens have at the same time a pro-immunogenic and an anti-immunogenic effect $(67,68)$.

\section{Tumor microenvironment-related resistance to treatment in head and neck cancers}

Resistance to therapy represents an ongoing and difficult challenge in HNSCC patients, despite major advances in therapy.

The pathways of resistance to conventional therapies such as chemotherapy, radiotherapy, and EGFR inhibitors, are well known and complex. But the resistance mechanisms to the latest treatment options, immunotherapy, have recently come into attention. These mechanisms of resistance are related to impaired intra-tumoral immune infiltration, insufficient production and presentation of neo-antigens, upregulation of alternative immune checkpoints, T-cell exhaustion, epigenetic changes, impaired signaling of interferon- $\gamma($ IFN- $\gamma)$ or immune factors within the tumor microenvironment, all interfering with the response to immunotherapy $(6,68-70)$.

The possible mechanisms responsible for the resistance of HNSCC to immune checkpoint inhibitors (ICIs) described in studies are: i) loss of the PTEN which blocks T-cell infiltration secondary to the expression of VEGF and CCL2; ii) decrease in CCL4 production due to the alterations in $\beta$-catenin/WNT 
signaling pathway which prevent dendritic cell infiltration; iii) the presence of high levels of alternative co-inhibitory receptors on T cells, such as CTLA-4 or lymphocyte-activation gene 3 (LAG3) responsible for T cell exhaustion; iv) the implication of tumor-associated macrophages and T-regs $(71,72)$.

As the resistance to ICIs develops, an increased number of effector memory $\mathrm{T}$ cells $\mathrm{CD} 8^{+}$, a lower $\mathrm{CD} 4^{+} / \mathrm{CD} 8^{+}$ratio, and a supra-expression of TIM- 3 on $\mathrm{CD} 4^{+}$and $\mathrm{CD}^{+} \mathrm{T}$ cells are found within the tumor microenvironment $(6,73,74)$.

Depletion of T-regulatory tumor-infiltrating cells and the increase in the T-effector cell/T-regulatory cell ratio using an anti-CD25 antibody appears to improve the response to ICIs $(70,75)$.

Recent studies have demonstrated high programmed death ligand 1 (PD-L1) expression on tumor-related macrophages $\mathrm{CD}^{+} 8^{+}$, on $\mathrm{CD} 8^{+} \mathrm{TILs}$, and also on tumor cells from the crypts of the tonsils. Crypts of the tonsils are found to be the primary site of HPV infection. Literature data suggest that crypts of tonsils are responsible for the immune-evasion and escape of the HPV-infected cells (76).

Hypoxia represents an important element of the tumor microenvironment in HNSCC, with a defining role in the development of drug resistance, including chemo-radiotherapy and immunotherapy, due to the increased expression of hypoxia-inducible factor (HIF) $1 \alpha$ and $2 \alpha$. Both factors are known to have an impact on innate, as well as on adaptive immune systems, by controlling the infiltration of T lymphocytes and macrophages in the tumors (73).

Other factors implicated in resistance to treatment, including chemotherapy and radiotherapy, are the microRNAs secreted by the tumor and the stromal cells. microRNAs control growth, proliferation, angiogenesis, and immune surveillance. Recent studies have also shown that HPV-positive patients have different miRNA profiles compared to HPV-negative, and therefore different responses to treatment $(77,78)$.

\section{Strategies to fight TME: Treatment resistance in head and neck cancers}

Tumor progression, metastasis, and response to therapy are all processes influenced by the complex ecosystem that the tumor microenvironment represents and by the interactions between cellular and non-cellular components of this system.

HPV-positive tumors are known to be immune-enriched and therefore more responsive to chemo-radiotherapy, compared with HPV-negative tumors $(79,80)$.

Recent data have shown that high expression of PD-L1 and PD-L2 are found on fibroblasts and cancer cells, and this is implicated in the immunosuppressive state of these tumors (81).

Different immunotherapies, directed to immune checkpoints such as programmed cell death-1 (PD-1), PD-L1, and cytotoxic T-lymphocyte-associated protein 4 (CTLA-4) are currently evaluated in clinical trials trying to increase cancer-specific immunity in HNSCC. Because of the differences found in HPV-positive and HPV-negative HNSCC patients in terms of tumor mutational burden (TMB) or immunologic landscape, the results are disparate.

PD-L1, which is supra-expressed in more than $65 \%$ of HNSCC patients, represents the ligand for PD-1 and PD-2 and decreases T-cell activation during inflammation. PD-L1 is found to be overexpressed more frequently in HPV-positive HNSCC.

Durvalumab has been evaluated on platinum-refractory recurrent and metastatic HNSCC patients (HAWK trial), with the results showing a better overall response rate (ORR) of $30 \%$ in HPV-positive patients, compared with an ORR of $10 \%$ in HPV-negative patients (82).

In the same manner, anti-PD-1 pembrolizumab and nivolumab, approved by the FDA, have also shown an improvement in the OS of HPV-positive recurrent and metastatic HNSCC compared to HPV-negative patients $(83,84)$.

Combination therapies have synergistically enhanced the immunological antitumor effects. The double blockade therapy, targeting both co-stimulatory and inhibitory receptors (PD-L1, CTLA-4), brings together for example durvalumab (MEDI4736) and tremelimumab, a combination trying to potentiate antitumor activity, without negatively impacting the safety in patients. Yet, to date, this combination has not meet primary objectives (OS, ORR) in 2 phase 3 clinical trials (NCT02551159, NCT02369874) in patients with recurrent and metastatic HNSCC (85).

The combination of nivolumab and ipilimumab compared to standard therapy (cetuximab + platinum +5 fluorouracil) is under investigation in first-line recurrent or metastatic HNSCC (NCT02741570).

Triple combination using nivolumab, ipilimumab, and relatlimab (anti-LAG3 monoclonal antibody, also called BMS-986016) is also being evaluated in head and neck cancer patients (NCT02488759).

Another research direction in clinical trials, based on the knowledge that anti-OX40 and anti-CD27 agents activate OX40 and CD27 and promote T-cell proliferation, is the assessment of the safety and tolerability of durvalumab combined with agonistic anti-OX40 Ab (MEDI6383) in solid tumors including head and neck cancers (NCT02221960). In addition, varlilumab, an agonistic anti-CD27 monoclonal antibody has been evaluated in combination with nivolumab for clinical benefit, safety, and tolerability in solid tumors including HNSCC patients (NCT02335918).

Standard chemo-radiotherapy is responsible for the induction of cancer cell death and promotes antitumoral immune responses by depleting cytotoxic lymphocytes, increasing myeloid-derived suppressor cells, and enhancing the expression of MHC I in tumors (86). Recent data show that using lower doses of chemo-radiotherapy also triggers both adaptative and innate immune responses and improves the immune recognition of dying cancer cells, by mobilizing hematopoietic lymphoid and myeloid cells from the bone marrow. The result is an increased infiltration by $\mathrm{T}$ cells $\left(\mathrm{CD} 4^{+}\right.$and $\left.\mathrm{CD}^{+}\right)$and dendritic cells, secretion of INF- $\gamma$ and IL-2, and elimination of myeloid-derived suppressor cells $(87,88)$.

Administration of cetuximab was found to result in decreased cancer cell proliferation and inhibition of neo-angiogenesis which lowered the risk of progression to metastatic disease. Cetuximab also has a role in the improvement of the immune response by promoting T-cell priming and NK cell activation, the result being increased survival of HNSCC patients (89). 
Clinical trial KEYNOTE-048 evaluated pembrolizumab (MK-3475) alone or with chemotherapy vs. cetuximab with chemotherapy in recurrent or metastatic HNSCC patients. The results of the trial showed that pembrolizumab in combination with chemotherapy improved OS compared to cetuximab with chemotherapy in the total population (13 months vs. 10.7 months), and pembrolizumab as monotherapy is an appropriate first-line treatment for PD-L1-positive recurrent or metastatic HNSCC (90).

Radiotherapy increases PD-L1 expression and based on the immunomodulatory effects of radiotherapy, the combination of radiotherapy with ICIs is under evaluation in clinical trials. In the light of this informations, the NCT02684253 clinical trial is evaluating the combination of nivolumab with stereotactic radiotherapy. Other clinical trials were designed to evaluate the combination of intensity-modulated radiation therapy (IMRT) with chemotherapeutic agents such as cisplatin (NCT02764593), the combination of ipilimumab, and cetuximab with IMRT (NCT01860430 and NCT01935921), or the combination of pembrolizumab, cisplatin, and IMRT (NCT02777385) in HNSCC patients. Another combination under investigation is atezolizumab and bevacizumab in patients with HPV or EBV-associated HNSCC (NCT03074513).

The combination of cell cycle regulators, CDK4/6 inhibitors (abemaciclib or palbociclib), a PD-L1 inhibitor (avelumab), and cetuximab is under evaluation in HNSCC patients (NCT03498378).

Epidermal growth factor receptor (EGFR) is overexpressed in approximately $90 \%$ of HNSCC patients and is associated with the aggressive behavior of the cancer, resistance to radiotherapy, and a negative prognosis $(91,92)$. The relationship between EGFR expression and HPV status of HNSCC tumors is not yet fully understood. Some studies reported increased EGFR amplification in p16-negative oropharyngeal cancers and reported better outcomes for HPV-positive HNSCC patients with low EGFR expression $(93,94)$. Many clinical trials are evaluating the role of other EGFR inhibitors such as panitumumab or nimotuzumab. In addition, small-molecule inhibitors such as, afatinib, erlotinib, gefitinib, or lapatinib are under investigation either alone or in combination with chemotherapy (95).

Even if many diagnostic or prognostic biomarkers have been identified, only a few are validated and can be used in current practice. HPV detection and p16 overexpression (a surrogate biomarker for HPV infection) are commonly used in practice. Positivity of p16 was included in the WHO TNM classification for oropharyngeal cancers $(6,96)$.

Immune gene expression and tumor mutational burden (TMB) characterize the functional state of immune cells within the tumor microenvironment and they can be used as predictive biomarkers for immunotherapy. Analysis of immune gene expression profile is based on extracted RNA and represents the $\mathrm{T}$ cell activation status within the tumor microenvironment. It seems that high immune gene expression can predict anti-PD1 efficacy in multiple tumor types. The TMB represents the number of somatic mutations per DNA megabase and is a promising predictive biomarker for immunotherapy. A higher mutation number is correlated with a better response to immunotherapy; information collected from patients with non-small cell lung cancer (NSCLC) who received treatment with nivolumab suggests a better progression-free survival, regardless of the PD-L1 expression status. In HNSCC clinical trials in patients receiving pembrolizumab, data showed that TMB was one of the most important parameters associated with the best overall response.

TMB is different in HPV-positive patients compared with HPV-negative patients; a higher TMB was observed in HPV-negative HNSCC cancers $(5,47,48)$, but the clinical significance of this data requires further validation in clinical trials. Longer median survival was observed in HNSCC patients with TMB $>10$ mutations/Mb than in patients with TMB $>5$ mutations/Mb (20 vs. 6 months). Virus-positive patients (HPV positive/Epstein Barr positive) had a lower TMB than virus-negative patients and improved OS. Among virus-negative patients, TMB $>10$ mutations/Mb had higher survival. In HPV-positive patients, TMB status did not influence survival. Although smokers have higher TMB levels compared with non-smokers, the response to immunotherapy could not be predicted by smoking status (97-99).

\section{Tumor immune infiltration}

Multiple immune cells coexist within the tumoral microenvironment: NK cells, APC, TILs (CD8 T cells and T-regs), macrophages, and myeloid-derived suppressor cells. Although HNSCC tumors are highly immune-infiltrated, they are characterized by an immunosuppressive TME. Patients with HPV-positive tumors have a higher density of $\mathrm{CD} 20^{+} \mathrm{B}$ cells and $\mathrm{CD} 8^{+} \mathrm{T}$ cells. Despite many attempts to assess the predictive and prognostic role of tumor immune cell infiltration, only increased infiltration by $\mathrm{CD}^{+}$was proven to correlate with better survival. A retrospective evaluation of 126 patients with recurrent and metastatic HNSCC treated with anti-PD-1/PD-L1 agents revealed an increased expression of $\mathrm{CD}^{+} \mathrm{T}$ cells/T-regs and this feature was correlated with treatment response. The immuno-score (IS) quantifies the density of $\mathrm{CD}^{+} \mathrm{T}$ cells within the tumor center vs. the invasive margin. In HNSCC, a high IS is associated with increased MHC type I and PD-L1, lower levels of T-regs, but the predictive role has not yet been explored (100).

In melanoma and NSCLC, the co-expression of inhibitory immune-checkpoint molecules as T-cell immunoglobulin and mucin domain-containing protein 3 (TIM-3), T-cell immunoreceptor with Ig and ITIM domains (TIGIT), lymphocyte-activating gene 3 (LAG-3) has a role in immune T cell-mediated responses, and these patients have resistance to anti-PD-1/PD-L1. In HNSCC, data collected by a recent study demonstrated that TIM-3 and LAG-3 expression was higher among patients with a poor response to anti-PD-1 therapy.

Immunophenotyping of circulating T-cell subset compared with TILs demonstrated a predictive role in response to immunotherapy in melanoma and NSCLC, but without certain data in HNSCC. In the CHECKMATE-141 trial (Trial of Nivolumab vs. Therapy of Investigator's Choice in Recurrent or Metastatic Head and Neck Carcinoma), the responders had lower levels of circulating PD-1, CD8 ${ }^{+} \mathrm{T}$ cells at baseline and lower levels of PD-1, T-regs at day 43. These data show that lower levels of circulating $\mathrm{T}$ cells are negative predictive biomarkers $(101,102)$. 


\section{6. $T$ cell-inflamed gene expression profile}

In light of the previous studies, the gene expression profile of tumors shows valuable information for predicting patient prognosis and treatment response. Tumors with an inflamed phenotype are more sensitive to anti-PD-1/PD-L1 agents. HPV-positive patients have higher cytolytic activity than HPV-negative patients. Interferon- $\gamma$ related gene signatures are closely related to HPV-positive status; immunosuppressive IL-6/TGF- $\beta$ related gene signatures are related to HPV-negative status.

Tumors with a T-cell inflamed phenotype, determined by gene-expression profiling, appear to have better responses to anti-PD-1/PD-1 therapy. KEYNOTE-012 and KEYNOTE-055 trials, which included patients with HNSCC treated with pembrolizumab, showed an 18-gene T-cell-inflamed signatures (including genes that reflect an ongoing adaptive $\mathrm{Th} 1$ and cytotoxic $\mathrm{CD} 8^{+} \mathrm{T}$-cell response) that positively correlated with response and survival. The predictive value of gene expression panel (GEP) and TMB were each independently associated with response, but responses were higher in patients that had both high TMB and $\operatorname{GEP}(103,104)$.

\section{Microsatellite instability (MSI)}

Microsatellite instability (MSI) is the condition of genetic hypermutability that results from impaired DNA mismatch repair. The incidence of tumors with high MSI (MSI-H) has been estimated at $8 \%$ in patients with HNSCC tumors. Tumors with MSI or mismatch repair deficiency (dMMR), have the highest mutation load and are sensitive to immunotherapy. Based on these data obtained from clinical trials, pembrolizumab was approved for patients with dMMR or MSI-H tumors, regardless of histology. A retrospective analysis showed that in HNSCC, patients with high MSI have a durable response after immunotherapy (105-107).

\section{Microbiota}

Although the mechanism is unknown, the composition of the microbiota and the compositional and functional changes in the microbiota can be associated with immune dysregulation, initiation, and progression of many types cancers. In addition, the intestinal microbiota can regulate the anticancer response of the host and the response to treatment. HNSCC arises from the epithelium that is constantly exposed to environmental factors that can affect oral microbiota. Studies have shown differences in saliva composition in patients with HNSCC and healthy patients. Differences between microbiota composition in the saliva have been observed in HPV-positive patients compared to HPV-negatives patients. A study analyzing saliva composition in normal, primary tumor, and metastatic HNSCC demonstrated an abundance of Fusobacterium and Lactobacillus, downregulation of immune signaling pathways, and upregulation of the oncogenic Wnt/ $\beta$-catenin pathways, in primary and metastatic cancer issues, whereas the abundance of Streptococcus was significantly decreased (108-110). CHECKMATE-141 is the only study that has explored the role of oral microbiota as a predictive biomarker in patients with recurrent and metastatic HNSCC treated with nivolumab. No significant correlation with treatment efficacy or survival was found (83).

\section{Smoking status}

Tabaco use is one of the major risk factors involved in the development of HNSCC through its pro-inflammatory and immune-suppressive effects. Smoking causes enriched immunogenic neoantigens and higher overall mutational loads. Smoker patients with HNSCC have lower levels of immune infiltration, cytolytic activity, and IFN- $\gamma$ pathway activation comparing to non-smokers counterparts. In CHECKMATE-141 smokers had an inferior response to nivolumab comparing with non-smokers $(66,83)$.

\section{Conclusions}

In the early stages, after local treatment, many of the patients with HNSCC have satisfying outcomes. Some patients with locally advanced disease will be cured by a combination of surgery, chemotherapy, and radiation, while others will develop recurrent or metastatic disease within the first three years after treatment. The poor outcomes, the high frequency of relapse after conventional treatment methods, and resistance to treatment have led to a call for research to understand the tumor biology of HNSCC and overcome the poor prognosis of these patients.

In the last few years, there have been growing efforts to characterize the tumor microenvironment, to identify targets of response and identify other mechanisms of tumor-specific immune responses, or to discover biomarkers of response. There is an urgent need to understand how to properly select patients, sequence therapy, and how to use feasible biomarkers that can help identify patients who may obtain the most benefit from available therapies. Many studies have demonstrated that the tumor microenvironment of HNSCC is heterogeneous and very immunosuppressive.

As the tumor microenvironment, in light of the recent data, is not an 'innocent observer', but an important player representing a suitable environment for formation, progression of cancer, and treatment resistance, many clinical trials are trying to discover a better solution for HNSCC patients, and this includes the evaluation of different signaling pathways within the tumor microenvironment and understand it's biology. The tumor microenvironment can offer a wide spectrum of novel anticancer therapies, not only for HNSCC patients but also for other cancers.

Future studies are necessary to establish the complex role of the tumor microenvironment to defeat treatment resistance and to help develop new therapeutic strategies.

\section{Acknowledgements}

Not applicable.

\section{Funding}

Not applicable. 


\section{Availability of data and materials}

All information is documented by relevant references.

\section{Authors' contributions}

LM and SMN were responsible for the original draft preparation and the literature findings. LM, AIS, DLS, ADG, GF and SMN were responsible for the final review of the literature data and the manuscript editing. All authors read and approved the final manuscript for publication.

\section{Ethics approval and consent to participate}

Not applicable.

\section{Patient consent for publication}

Not applicable.

\section{Competing interests}

The authors declare that they have no competing interests.

\section{References}

1. Siegel RL, Miller KD and Jemal A: Cancer Statistics, 2020. CA Cancer J Clin 70: 7-30, 2020.

2. Bray F, Ferlay J, Soerjomataram I, Siegel RL, Torre LA and Jemal A: Global cancer statistics 2018: GLOBOCAN estimates of incidence and mortality worldwide for 36 cancers in 185 countries. CA Cancer J Clin 68: 394-424, 2018.

3. Ghantous Y and Abu Elnaaj I: Global incidence and risk factors of oral cancer. Harefuah 156: 645-649, 2017.

4. Haddad RI and Shin DM: Recent advances in head and neck cancer. N Engl J Med 359: 1143-1154, 2008.

5. Bhat AA, Yousuf P, Wani NA, Rizwan A, Chauhan S, Siddiqi MA Bedognetti D, El-Rifai W, Frenneaux MP, Batraet SK, et al: Tumor microenvironment: An evil nexus promoting aggressive head and neck squamous cell carcinoma and avenue for targeted therapy. Signal Transduct Target Ther 6: 12, 2021.

6. Wang HC, Chan LP and Cho SF: Targeting the immune microenvironment in the treatment of head and neck squamous cell carcinoma. Front Oncol 9: 1084, 2019.

7. Solomon I, Voiculescu VM, Caruntu C, Lupu M, Popa A, Ilie MA, Albulescu R, Caruntu A, Tanase C, Constantin C, et al: Neuroendocrine factors and head and neck squamous cell carcinoma: An affair to remember. Dis Markers 2018: 9787831, 2018.

8. Hsu WL, Yu KJ, Chiang CJ, Chen TC and Wang CP: Head and neck cancer incidence trends in Taiwan, 1980-2014. Int J Head Neck Sci 1: 180-189, 2017.

9. Chaturvedi AK, Engels EA, Pfeiffer RM, Hernandez BY, Xiao W, Kim E, Jiang B, Goodman MT, Sibug-Saber M, Cozen W, et al: Human papillomavirus and rising oropharyngeal cancer incidence in the United States. J Clin Oncol 29: 4294-4301, 2011

10. Hashibe M, Brennan P, Chuang SC, Boccia S, Castellsague X, Chen C, Curado MP, Dal Maso L, Daudt AW, Fabianova E, et al: Interaction between tobacco and alcohol use and the risk of head and neck cancer: Pooled analysis in the international head and neck cancer epidemiology consortium. Cancer Epidemiol Biomarkers Prev 18: 541-550, 2009.

11. Maier H, Dietz A, Gewelke U, Heller WD and Weidauer H: Tobacco and alcohol and the risk of head and neck cancer. Clin Investig 70: 320-327, 1992.

12. Sturgis EM and Wei Q: Genetic susceptibility-molecular epidemiology of head and neck cancer. Curr Opin Oncol 14: 310-317, 2002.

13. Preston-Martin S, Thomas DC, White SC and Cohen D: Prior exposure to medical and dental x-rays related to tumors of the parotid gland. J Natl Cancer Inst 80: 943-949, 1988.
14. Boffetta P, Richiardi L, Berrino F, Estève J, Pisani P, Crosignani P, Raymond L, Zubiri L, Del Moral A, Lehmannet W, et al: Occupation and larynx and hypopharynx cancer: An international case-control study in France, Italy, Spain, and Switzerland Cancer Causes Control 14: 203-212, 2003.

15. Chien YC, Chen JY, Liu MY, Yang HI, Hsu MM, Chen CJ and Yanget CS: Serologic markers of Epstein-Barr virus infection and nasopharyngeal carcinoma in Taiwanese men. N Engl J Med 345: 1877-1882, 2001.

16. Kobayashi I, Shima K, Saito I, Kiyoshima T, Matsuo K, Ozeki S, Ohishi M and Sakai H: Prevalence of Epstein-Barr virus in oral squamous cell carcinoma. J Pathol 189: 34, 1999.

17. Mahale P, Sturgis EM, Tweardy DJ, Ariza-Heredia EJ and Torres HA: Association between hepatitis $\mathrm{C}$ virus and head and neck cancers. J Natl Cancer Inst 108: djw035, 2016.

18. Vermorken JB, Mesia R, Rivera F, Remenar E, Kawecki A, Rottey S, Erfan J, Zabolotnyy D, Kienzer HR, Cupissol D, et al: Platinum-based chemotherapy plus cetuximab in head and neck cancer. N Engl J Med 359: 1116-1127, 2008.

19. Chow LQM, Haddad R, Gupta S, Mahipal A, Mehra R, Tahara M, Berger R, Eder JP, Burtness B, Lee SH, et al: Antitumor activity of pembrolizumab in biomarker-unselected patients with recurrent and/or metastatic head and neck squamous cell carcinoma: Results from the phase Ib KEYNOTE-012 expansion cohort. J Clin Oncol 34: 3838-3845, 2016.

20. Ferris RL, Blumenschein GR, Fayette J, Guigay J, Colevas AD, Licitra LF, Harrington KJ, Kasper S, Vokes EE, Even C, et al: Further evaluations of nivolumab (nivo) versus investigator's choice (IC) chemotherapy for recurrent or metastatic (R/M) squamous cell carcinoma of the head and neck (SCCHN): Check Mate 141. Am Soc Clin Oncol 34 (Suppl 15): S6009, 2016.

21. $\mathrm{Wu} \mathrm{T}$ and Dai Y: Tumor microenvironment and therapeutic response. Cancer Lett 387: 61-68, 2017.

22. Soysal SD, Tzankov A and Muenst SE: Role of the tumor microenvironment in breast cancer. Pathobiology 82: 142-152, 2015.

23. Denton AE, Roberts EW and Fearon DT: Stromal cells in the tumor microenvironment. Adv Exp Med Biol 1060: 99-114, 2018.

24. Hanahan D and Weinberg RA: Hallmarks of cancer: The next generation. Cell 144: 646-674, 2011.

25. Peltanova B, Raudenska M and Masarik M: Effect of tumor microenvironment on pathogenesis of the head and neck squamous cell carcinoma: A systematic review. Mol Cancer 18: 63 , 2019.

26. Giancotti FG: Deregulation of cell signaling in cancer. FEBS Lett 588: 2558-2570, 2014.

27. Arneth B: Tumor microenvironment. Medicina (Kaunas) 56: 15, 2019.

28. Ludwig S, Sharma P, Theodoraki MN, Pietrowska M, Yerneni SS Lang S, Ferrone S and Whitesideet TL: Molecular and functional profiles of exosomes from HPV (+) and HPV (-) head and neck cancer cell lines. Front Oncol 8: 445, 2018.

29. Keck MK, Zuo Z, Khattri A, Stricker TP, Brown CD, Imanguli M, Rieke D, Endhardt K, Fang P, Brägelmann J, et al: Integrative analysis of head and neck cancer identifies two biologically distinct HPV and three non-HPV subtypes. Clin Cancer Res 21: 870-881, 2015.

30. Cristina V, Herrera-Gómez RG, Szturz P, Espeli V and Siano M: Immunotherapies and future combination strategies for head and neck squamous cell carcinoma. Int J Mol Sci 20: 5399,2019

31. Chaudhary S, Ganguly K, Muniyan S, Pothuraju R, Sayed Z, Jones DT, Batra SK and Macha MA: Immunometabolic alterations by HPV infection: New dimensions to head and neck cancer disparity. J Natl Cancer Inst 111: 233-244, 2019.

32. Quezada SA, Peggs KS, Simpson TR and Allison JP: Shifting the equilibrium in cancer immunoediting: From tumor tolerance to eradication. Immunol Rev 241: 104-118, 2011

33. Dobrenis K, Gauthier LR, Barroca V and Magnon C: Granulocyte colony-stimulating factor off-target effect on nerve outgrowth promotes prostate cancer development. Int J Cancer 136: 982-988, 2015

34. Hu P, Wang G, Shen M, Zhang P, Zhang J, Du J and Liu Q: Intratumoral polymorphonuclear granulocyte is associated with poor prognosis in squamous esophageal cancer by promoting epithelial-mesenchymal transition. Future Oncol 11: 771-783, 2015.

35. Fang J, Li X, Ma D, Liu X, Chen Y, Wang Y, Yan Lui VW, Xia J, Cheng B and Wang Z: Prognostic significance of tumor infiltrating immune cells in oral squamous cell carcinoma. BMC Cancer 17: 375, 2017. 
36. Sakakura K, Chikamatsu K, Takahashi K, Whiteside TL and Furuya N: Maturation of circulating dendritic cells and imbalance of T-cell subsets in patients with squamous cell carcinoma of the head and neck. Cancer Immunol Immunother 55: 151-159, 2006.

37. Whiteside TL: Immunobiology of head and neck cancer. Cancer Metastasis Rev 24: 95-105, 2005.

38. Oweida A, Hararah MK, Phan A, Binder D, Bhatia S, Lennon S, Bukkapatnam S, Van Court B, Uyanga N, Darraghet L, et al: Resistance to radiotherapy and PD-L1 blockade is mediated by TIM-3 upregulation and regulatory T-cell infiltration. Clin Cancer Res 24: 5368-5380, 2018.

39. Echarri M, Lopez-Martin A and Hitt R: Targeted therapy in locally advanced and recurrent/metastatic head and neck squamous cell carcinoma (LA-R/M HNSCC). Cancers (Basel) 8: 27, 2016.

40. Kather JN, Suarez-Carmona M, Charoentong P, Weis CA, Hirsch D, Bankhead P, Horning M, Ferber D, Kel I, Herpel E, et al Topography of cancer-associated immune cells in human solid tumors. Elife 7: e36967, 2018.

41. Johnson SD, De Costa AM and Young MR: Effect of the premalignant and tumor microenvironment on immune cell cytokine production in head and neck cancer. Cancers (Basel) 6: 756-770, 2014.

42. Bonomi M, Patsias A, Posner M and Sikora A: The role of inflammation in head and neck cancer. Adv Exp Med Biol 816: 107-127, 2014.

43. Boda D, Docea AO, Calina D, Ilie MA, Caruntu C, Zurac S, Neagu M, Constantin C, Branisteanu DE, Voiculescu V, et al: Human papilloma virus: Apprehending the link with carcinogenesis and unveiling new research avenues (Review). Int J Oncol 52: 637-655, 2018.

44. Carpén T, Sjöblom A, Lundberg M, Haglund C, Markkola A, Syrjänen S, Tarkkanen J, Mäkitie A, Hagström J and Mattila P: Presenting symptoms and clinical findings in HPV-positive and HPV-negative oropharyngeal cancer patients. Acta Otolaryngol 138: 513-518, 2018.

45. Panwar A, Batra R, Lydiatt WM and Ganti AK: Human papilloma virus positive oropharyngeal squamous cell carcinoma: A growing epidemic. Cancer Treat Rev 40: 215-219, 2014.

46. Pytynia KB, Dahlstrom KR and Sturgis EM: Epidemiology of HPV-associated oropharyngeal cancer. Oral Oncol 50: 380-386, 2014.

47. Cancer Genome Atlas Network: Comprehensive genomic characterization of head and neck squamous cell carcinomas. Nature 517: 576-582, 2015.

48. Seiwert TY, Zuo Z, Keck MK, Khattri A, Pedamallu CS, Stricker T, Brown C, Pugh TJ, Stojanov P, Cho J, et al: Integrative and comparative genomic analysis of HPV-positive and HPV-negative head and neck squamous cell carcinomas. Clin Cancer Res 21: 632-641, 2015.

49. Weinberger PM, Yu Z, Haffty BG, Kowalski D, Harigopal M, Brandsma J, Sasaki C, Joe J, Camp RL, Rimmet DL, et al: Molecular classification identifies a subset of human papillomavirus-associated oropharyngeal cancers with favorable prognosis. J Clin Oncol 24: 736-747, 2006.

50. Mandal R, Senbabaoğlu Y, Desrichard A, Havel JJ, Dalin MG, Riaz N, Lee K-W, Ganly I, Hakimi AA, Chan TA and Morris LG: The head and neck cancer immune landscape and its immunotherapeutic implications. JCI Insight 1: e89829, 2016.

51. Koneva LA, Zhang Y, Virani S, Hall PB, McHugh JB, Chepeha DB, Wolf GT, Carey TE, Rozek LS and Sartor MA: HPV integration in HNSCC correlates with survival outcomes, immune response signatures, and candidate drivers. Mol Cancer Res 16: 90-102, 2018

52. Kindt N, Descamps G, Seminerio I, Bellier J, Lechien JR, Mat Q, Pottier C, Delvenne P, Journé F and Saussez S: High stromal Foxp3-positive T cell number combined to tumor stage improved prognosis in head and neck squamous cell carcinoma. Oral Oncol 67: 183-191, 2017.

53. Seminerio I, Descamps G, Dupont S, de Marrez L, Laigle JA Lechien JJ, Kindt N, Journe F and Saussez S: Infiltration of Fox $3^{+}$regulatory $\mathrm{T}$ cells is a strong and independent prognostic factor in head and neck squamous cell carcinoma. Cancers (Basel) 11: 227, 2019.

54. Punt S, Dronkers EA, Welters MJ, Goedemans R, Koljenović S, Bloemena E, Snijders PJ, Gorter A, van der Burg SH, Baatenburg de Jong RJ and Jordanova ES: A beneficial tumor microenvironment in oropharyngeal squamous cell carcinoma is characterized by a high T cell and low IL-17(+) cell frequency. Cancer Immunol Immunother 65: 393-403, 2016.
55. Oguejiofor K, Hall J, Slater C, Betts G, Hall G, Slevin N, Dovedi S, Stern PL and Westet CM: Stromal infiltration of CD8 T cells is associated with improved clinical outcome in HPV-positive oropharyngeal squamous carcinoma. Br J Cancer 113: 886-893, 2015.

56. Lechien JR, Descamps G, Seminerio I, Furgiuele S, Dequanter D, Mouawad F, Badoual C, Journe F and Saussez S: HPV Involvement in the tumor microenvironment and immune treatment in head and neck squamous cell carcinomas. Cancers 12: $1060,2020$.

57. Wolf GT, Chepeha DB, Bellile E, Nguyen A, Thomas D and McHugh J: Tumor infiltrating lymphocytes (TIL) and prognosis in oral cavity squamous carcinoma: A preliminary study. Oral Oncol 51: 90-95, 2015.

58. Seminerio I, Kindt N, Descamps G, Bellier J, Lechien JR, Mat Q, Pottier C, Journé F and Saussez S: High infiltration of CD68 ${ }^{+}$ macrophages is associated with poor prognoses of head and neck squamous cell carcinoma patients and is influenced by human papillomavirus. Oncotarget 9: 11046-11059, 2018.

59. WagnerS,WittekindtC,ReuschenbachM,Hennig B,ThevarajahM, Würdemann N, Prigge ES, von Knebel Doeberitz M, Dreyer T, Gattenlöhneret S, et al: CD56-positive lymphocyte infiltration in relation to human papillomavirus association and prognostic significance in oropharyngeal squamous cell carcinoma. Int J Cancer 138: 2263-2273, 2016

60. Guess JC and McCance DJ: Decreased migration of Langerhans precursor-like cells in response to human keratinocytes expressing human papillomavirus type $16 \mathrm{E} 6 / \mathrm{E} 7$ is related to reduced macrophage inflammatory protein-3alpha production. J Virol 79: 14852-14862, 2005

61. Kindt N, Descamps G, Seminerio I, Bellier J, Lechien JR, Pottier C, Larsimont D, Journé F, Delvenne P and Saussez S: Langerhans cell number is a strong and independent prognostic factor for head and neck squamous cell carcinomas. Oral Oncol 62: 1-10, 2016.

62. Matthews K, Leong CM, Baxter L, Inglis E, Yun K, Bäckström T, Doorbar $\mathrm{J}$ and Hibma M: Depletion of Langerhans cells in human papillomavirus type 16-infected skin is associated with E6-mediated down regulation of E-cadherin. J Virol 77: 8378-8385, 2003.

63. Kanodia S, Fahey LM and Kast WM: Mechanisms used by human papillomaviruses to escape the host immune response. Curr Cancer Drug Targets 7: 79-89, 2007.

64. Wellenstein MD and de Visser KE: Cancer-cell-intrinsic mechanisms shaping the tumor immune landscape. Immunity 48 : 399-416, 2018.

65. Outh-Gauer S, Morini A, Tartour E, Lépine C, Jung AC and Badoual C: The microenvironment of head and neck cancers: Papillomavirus involvement and potential impact of immunomodulatory treatments. Head Neck Pathol 14: 330-340, 2020.

66. Zimmermann M, Zouhair A, Azria D and Ozsahin M: The epidermal growth factor receptor (EGFR) in head and neck cancer: Its role and treatment implications. Radiat Oncol 1: 11, 2006.

67. Hernandez CP, Morrow K, Velasco C, Wyczechowska DD, Naura AS and Rodriguez PC: Effects of cigarette smoke extract on primary activated T cells. Cell Immunol 282: 38-43, 2013.

68. Desrichard A, Kuo F, Chowell D, Lee KW, Riaz N, Wong RJ, Chan TA and Morris L: Tobacco smoking-associated alterations in the immune microenvironment of squamous cell carcinomas. J Natl Cancer Inst 110: 1386-1392, 2018.

69. Sok JC, Coppelli FM, Thomas SM, Lango MN, Xi S, Hunt JL, Freilino ML, Graner MW, Wikstrand CJ, Bigner DD, et al: Mutant epidermal growth factor receptor (EGFRvIII) contributes to head and neck cancer growth and resistance to EGFR targeting. Clin Cancer Res 12: 5064-5073, 2006.

70. Koyama S, Akbay EA, Li YY, Herter-Sprie GS, Buczkowski KA Richards WG, Gandhi L, Redig AJ, Rodig SJ, Asahina H, et al: Adaptive resistance to therapeutic PD-1 blockade is associated with upregulation of alternative immune checkpoints. Nat Commun 7: 10501, 2016.

71. Jenkins RW, Barbie DA and Flaherty KT: Mechanisms of resistance to immune checkpoint inhibitors. Br J Cancer 118: 9-16, 2018.

72. Peng W, Chen JQ, Liu C, Malu S, Creasy C, Tetzlaff MT, Xu C, McKenzie JA, Zhang C, Liang X, et al: Loss of PTEN promotes resistance to T cell-mediated immunotherapy. Cancer Discov 6: 202-216, 2016.

73. Zaretsky JM, Garcia-Diaz A, Shin DS, Escuin-Ordinas H, Hugo W, Hu-Lieskovan S, Torrejon DY, Abril-Rodriguez G, Sandoval S, Barthly L, et al: Mutations associated with acquired resistance to PD-1 blockade in melanoma. N Engl J Med 375: 819-829, 2016. 
74. O'Donnell JS, Long GV, Scolyer RA, Teng MW and Smyth MJ: Resistance to PD1/PDL1 checkpoint inhibition. Cancer Treat Rev 52: 71-81, 2017.

75. Vargas FA, Furness AJ, Solomon I, Joshi K, Mekkaoui L, Lesko MH, Rota EM, Dahan R, Georgiou A, Sledzinska A, et al Fc-optimized anti-CD25 depletes tumor-infiltrating regulatory $\mathrm{T}$ cells and synergizes with PD-1 blockade to eradicate established tumors. Immunity 46: 577-586, 2017.

76. Lyford-Pike S, Peng S, Young GD, Taube JM, Westra WH, Akpeng B, Bruno TC, Richmon JD, Wang H, Bishopet JA, et al: Evidence for a role of the PD-1:PD-L1 pathway in immune resistance of HPV-associated head and neck squamous cell carcinoma. Cancer Res 73: 1733-1741, 2013.

77. Wan Y, Vagenas D, Salazar C, Kenny L, Perry C, Calvopiña D and Punyadeera C: Salivary miRNA panel to detect HPV-positive and HPV-negative head and neck cancer patients. Oncotarget 8: 99990-100001, 2017.

78. Vahabi M, Pulito C, Sacconi A, Donzelli S, D'Andrea M, Manciocco V, Pellini R, Paci P, Sanguineti G, Strigariet L, et al miR-96-5p targets PTEN expression affecting radio-chemosensitivity of HNSCC cells. J Exp Clin Cancer Res 38: 141, 2019.

79. Meulendijks D, Tomasoa NB, Dewit L, Smits PH, Bakker R, van Velthuysen ML, Rosenberg EH, Beijnen JH, Schellens JHM and Cats A: HPV-negative squamous cell carcinoma of the anal canal is unresponsive to standard treatment and frequently carries disruptive mutations in TP53. Br J Cancer 112: 1358-1366, 2015.

80. O'Sullivan B, Huang SH, Siu LL, Waldron J, Zhao H Perez-Ordonez B, Weinreb I, Kim J, Ringash J, Bayley A, et al: Deintensification candidate subgroups in human papillomavirus-related oropharyngeal cancer according to minimal risk of distant metastasis. J Clin Oncol 31: 543-550, 2013.

81. Baruah P, Bullenkamp J, Wilson P, Lee M, Kaski JC and Dumitriu IE: TLR9 mediated tumor-stroma interactions in human papilloma virus (HPV)-positive head and neck squamous cell carcinoma up-regulate PD-L1 and PD-L2. Front Immunol 10: 1644,2019

82. Zandberg DP, Algazi AP, Jimeno A, Good JS, Fayette J, Bouganim N, Ready NE, Clement PM, Even C, Janget RW, et al: Durvalumab for recurrent or metastatic head and neck squamous cell carcinoma: results from a single-arm, phase II study in patients with $>25 \%$ tumour cell PD-L1 expression who have progressed on platinum-based chemotherapy. Eur J Cancer 107: 142-152, 2019.

83. Ferris RL, Blumenschein G Jr, Fayette J, Guigay J, Colevas AD, Licitra L, Harrington K, Kasper S, Vokes EE, Even C, et al Nivolumab for recurrent squamous-cell carcinoma of the head and neck. N Engl J Med 375: 1856-1867, 2016.

84. Powell SF, Gold KA, Gitau MM, Sumey CJ,Lohr MM,McGraw SC, Nowak RK, Jensen AW, Blanchard MJ, Fischer CD, et al: Safety and efficacy of pembrolizumab with chemoradiotherapy in locally advanced head and neck squamous cell carcinoma: A phase IB study. J Clin Oncol 38: 2427-2437, 2020

85. Ferris RL, Haddad R, Even C, Tahara M,Dvorkin M,Ciuleanu TE Clement PM, Mesia R, Kutukova S, Zholudevaet L, et al: Durvalumab with or without tremelimumab in patients with recurrent or metastatic head and neck squamous cell carcinoma: EAGLE, a randomized, open-label phase III study. Ann Oncol 31: 942-950, 2020.

86. Siu LL, Even C, Mesía R, Remenar E, Daste A, Delord JP, Krauss J, Saba NF, Nabell L, Ready NE, et al: Safety and efficacy of durvalumab with or without tremelimumab in patients with PD-L1-Low/Negative recurrent or metastatic HNSCC: The phase 2 CONDOR randomized clinical trial. JAMA Oncol 5 : 195-203, 2019

87. Tsuchikawa T, Miyamoto M, Yamamura Y, Shichinohe $T$, Hirano S and Kondo S: The immunological impact of neoadjuvant chemotherapy on the tumor microenvironment of esophageal squamous cell carcinoma. Ann Surgical Oncol 19: 1713-1719, 2012.

88. Bracci L, Schiavoni G, Sistigu A and Belardelli F: Immune-based mechanisms of cytotoxic chemotherapy: Implications for the design of novel and rationale-based combined treatments against cancer. Cell Death Differ 21: 15-25, 2014

89. Concu R and Cordeiro M: Cetuximab and the head and neck squamous cell cancer. Curr Top Medicinal Chem 18: 192-198, 2018.

90. Burtness B, Harrington KJ, Greil R, Soulières D, Tahara M, de Castro G Jr, Psyrri A, Basté N, Neupane P, Bratland A, et al: Pembrolizumab alone or with chemotherapy versus cetuximab with chemotherapy for recurrent or metastatic squamous cell carcinoma of the head and neck (KEYNOTE-048): A randomised, open-label, phase 3 study. Lancet 394: 1915-1928, 2019.
91. Simsek H, Han Ü, Önal B and Simisek G: The expression of EGFR, cerbB2, p16, and p53 and their relationship with conventional parameters in squamous cell carcinoma of the larynx. Turkish J Med Sci 44: 411-416, 2014.

92. Liang K, Ang KK, Milas L, Hunter N and Fan Z: The epidermal growth factor receptor mediates radioresistance. Int J Radiat Oncol Biol Phys 57: 246-254, 2003.

93. Young RJ, Rischin D, Fisher R, McArthur GA, Fox SB, Peters LJ, Corry J, Lim A, Waldeck K and Solomon B: Relationship between epidermal growth factor receptor status, p16(INK4A), and outcome in head and neck squamous cell carcinoma. Cancer Epidemiol Biomark Prev 20: 1230-1237, 2011.

94. Kumar B, Cordell KG, Lee JS, Worden FP, Prince ME, Tran HH, Wolf GT, Urba SG, Chepeha DB, Teknoset TN, et al: EGFR, p16, HPV Titer, Bcl-xL and p53, sex, and smoking as indicators of response to therapy and survival in oropharyngeal cancer. J Clin Oncol 26: 3128-3137, 2008.

95. Bernier J, Bentzen SM and Vermorken JB: Molecular therapy in head and neck oncology. Nat Rev Clin Oncol 6: 266-277, 2009.

96. Henderson S, Chakravarthy A, Su X, Boshoff C and Fenton TR APOBEC-mediated cytosine deamination links PIK3CA helical domain mutations to human papillomavirus-driven tumor development. Cell Rep 7: 1833-1841, 2014.

97. Yarchoan M, Hopkins A and Jaffee EM: Tumor mutational burden and response rate to PD-1 inhibition. N Engl J Med 377 2500-2501, 2017.

98. Cristescu R, Mogg R, Ayers M, Albright A, Murphy E, Yearley J, Sher X, Liu XQ, Lu H, Nebozhynet M, et al: Pan-tumor genomic biomarkers for PD-1 checkpoint blockade-based immunotherapy. Science 362: eaar3593, 2018.

99. Li W, Wildsmith S, Ye J, Si H, Morsli N, He P, Shetty J, Yovine AJ, Holoweckyj N, Raja R, et al: Plasma-based tumor mutational burden (bTMB) as predictor for survival in phase III EAGLE study: Durvalumab (D) \pm tremelimumab (T) versus chemotherapy (CT) in recurrent/metastatic head and neck squamous cell carcinoma (R/M HNSCC) after platinum failure. J Clin Oncol 38: 6511, 2020.

100. Hladikova K, Koucky V, Boucek J, Laco J, Grega M, Hodek M, Zabrodsky M, Vosmik M, Rozkosova K, Vosmikova H, et al: Tumor-infiltrating B cells affect the progression of oropharyngeal squamous cell carcinoma via cell-to-cell interactions with CD8(+) T cells. J Immunother Cancer 7: 26, 2019.

101. Galon J, Fox BA, Bifulco CB, Masucci G, Rau T, Botti G, Marincola FM, Ciliberto G, Pages F, Ascierto PA and Capone M: Immunoscore and immunoprofiling in cancer: An update from the melanoma and immunotherapy bridge 2015 . J Transl Med 14: 273, 2016.

102. Zhang XM, Song LJ, Shen J, Yue H, Han YQ, Yang CL, Liu SY, Deng JW, Jiang Y, Fu GH and Shen WW: Prognostic and predictive values of immune infiltrate in patients with head and neck squamous cell carcinoma. Hum Pathol 82: 104-112, 2018

103. Jamieson NB and Maker AV: Gene-expression profiling to predict responsiveness to immunotherapy. Cancer Gene Ther 24: 134-140, 2017.

104. Prat A, Navarro A, Pare L, Reguart N, Galvan P, Pascual T, Martinez A, Nuciforo P, Comerma L, Alos L, et al: Immune-related gene expression profiling after PD-1 blockade in non-small cell lung carcinoma, head and neck squamous cell carcinoma, and melanoma. Cancer Res 77: 3540-3550, 2017.

105. Le DT, Durham JN, Smith KN, Wang H, Bartlett BR, Aulakh LK, Lu S, Kemberling H, Wilt C, Luber BS, et al: Mismatch repair deficiency predicts response of solid tumors to PD-1 blockade. Science 357: 409-413, 2017.

106. Le DT, Uram JN, Wang H, Bartlett BR, Kemberling H, Eyring AD, Skora AD, Luber BS, Azad NS, Laheru D, et al: PD-1 Blockade in tumors with mismatch-repair deficiency. N Engl J Med 372: 2509-2520, 2015.

107. Luchini C, Bibeau F, Ligtenberg MJ, Singh N, Nottegar A, Bosse T, Miller R, Riaz N, Douillard JY, Andre F, et al: ESMO recommendations on microsatellite instability testing for immunotherapy in cancer, and its relationship with PD-1/PD-L1 expression and tumour mutational burden: A systematic review-based approach. Ann Oncol 30: 1232-1243, 2019.

108. Roy S and Trinchieri G: Microbiota: A key orchestrator of cancer therapy. Nat Rev Cancer 17: 271-285, 2017.

109. Greenhill C: Gut microbiota: Anti-cancer therapies affected by gut microbiota. Nat Rev Gastroenterol Hepatol 11: 1, 2014.

110. Brandi G and Frega G: Microbiota: Overview and implication in immunotherapy-based cancer treatments. Int J Mol Sci 20: $2699,2019$. 